\title{
A RESILIÊNCIA DA SAÚDE MIGRANTE: ITINERÁRIOS TERAPÊUTICOS PLURAIS E TRANSNACIONAIS
}

\author{
Cláudia de Freitas* \\ Álvaro Mendes**
}

\begin{abstract}
Este artigo aborda as estratégias usadas no enfrentamento de problemas de saúde pelos imigrantes Cabo-verdianos na Holanda. Tendo por base uma metodologia qualitativa, discute-se a escolha de itinerários terapêuticos plurais, incluindo o uso decuidados informais, formais e transnacionais. Estes percursos são influenciados pelas racionalidades leigas dos Caboverdianos acerca da saúde, que assentam num "reportório Cristãoespiritual", e por um contexto sociocultural e político onde se impõem múltiplas barreiras no acesso aos cuidados de saúde formais Holandeses. A pluralidade de itinerários terapêuticos adotados pelos Cabo-verdianos objetiva-se na (re)construção de saberes leigos sobre a doença, na mobilização de recursos materiais e na ativação de recursos sociais locais e transnacionais. Esta pluralidade de estratégias é interpretada como uma evidência de resiliência destes imigrantes perante fatores adversos à manutenção do seu bem-estar mental, físico e espiritual.
\end{abstract}

Palavras-chave: Itinerários terapêuticos; Resiliência; Cuidados transnacionais; Imigrantes Cabo-verdianos; Holanda.

\section{Introdução}

Os países ocidentais conheceram nas últimas décadas um aumento exponencial de tecnologias, terapêuticas e serviços disponíveis para uso dos cidadãos na gestão da sua saúde. Além da diversificação e complexifi-

\footnotetext{
"Licenciada em Psicologia pela Universidade de Coimbra, Mestre em Migrações e Estudos Étnicos pela Universidade de Amesterdão, Doutorada em Ciências Sociais pela Universidade de Utrecht. Investigadora do Centro de Investigação e Estudos de Sociologia do Instituto Universitário de Lisboa. Bolseira de Pós-doutoramento da Fundação para a Ciência e Tecnologia. E-mail: claudia_ defreitas@yahoo.com. Lisboa/Portugal.

** Licenciado em Psicologia pela Universidade de Coimbra, Doutorado em Ciências da Saúde pela Universidade de Aveiro, Investigador do Centro de Genética Preditiva e Preventiva do Instituto de Biologia Molecular e Celular da Universidade do Porto. Bolseiro de Pós-doutoramento da Fundação para a Ciência e Tecnologia. E-mail: alvaro.mendes@ibmc.up.pt. Aveiro/Portugal.
} 
cação das respostas dos serviços inerentes a estes desenvolvimentos, tem-se observado, em alguns países, uma reformulação dos princípios norteadores da governação dos cuidados de saúde de acordo com a Nova Gestão Pública, que defende a aplicação de métodos de gestão empresarial (por exemplo, gestão por objetivos) e de mecanismos de mercado (tais como a competição, ou a contratualização de serviços) ao sector público. ${ }^{1}$ A livre escolha de serviços é um elemento central desta filosofia de governação que encara os utentes como consumidores, isto é, como indivíduos autónomos que são capazes de analisar, selecionar e utilizar os serviços que melhor servem os seus interesses, assim como de mostrar insatisfação quando esses serviços não respondem adequadamente às suas necessidades. Incorre, no entanto, que o exercício de escolhas no âmbito da gestão individual da saúde não depende somente do arbítrio dos utentes, nem tão pouco se esgota nos cuidados de saúde ditos formais, isto é, regulados pelo Estado e de cunho fortemente biomédico. As racionalidades leigas dos doentes, os recursos materiais e sociais acessíveis a quem procura cuidados e as políticas de saúde vigentes são fatores determinantes na identificação e escolha de percursos terapêuticos ${ }^{2}$ que podem facilitar ou impedir o acesso ao sistema biomédico dominante e/ou influenciar a seleção de opções fora deste. Porém, estes fatores nem sempre são considerados pelos decisores políticos a quem cabe planear e implementar serviços capazes de responder às necessidades de sociedades crescentemente diversas e heterogéneas por via dos processos de globalização e migração.

A ideia de que certos segmentos das populações ocidentais atuais, como por exemplo os imigrantes e as minorias étnicas, são demasiado tradicionalistas e pouco permeáveis à integração de outros referenciais culturais, ou até mesmo desprovidos das competências necessárias para fazerem uso dos modernos serviços de saúde existentes, ${ }^{3}$ é muitas vezes defendida com o objetivo omisso de legitimar políticas que negligenciam a necessidade de aumentar a competência cultural e a capacidade de resposta dos cuidados de saúde à diversidade, ou que o fazem de forma superficial. Tal cenário verifica-se em países como a Holanda, onde a eleição de um governo alinhado politicamente à direita, em 2004, levou a que o Estado se isentasse da responsabilidade que

${ }^{1}$ MCLAUGHLIN, Kate; OSBORNE, Stephen; FERLIE, Ewan. New public management: Current trends and future prospects.

2 CARAPINHEIRO, Graça. Inventar percursos, reinventar realidades: doentes, trajectórias sociais e realidades formais; INGLEBY, David et alii. The role of health in integration; GERHARDT, Tatiana. Itinerários terapêuticos em situações de pobreza: diversidade e pluralidade; SILVA, Luisa Ferreira da; ALVES, Fátima. Compreender as racionalidades leigas sobre saúde e doença; ALVES, Fátima; BÄCKSTRÖM, Bárbara. Lidar com a doença mental - a pluralidade de sistemas de cuidados e de itinerários terapêuticos.

${ }^{3}$ ELLIOT, Susan; GILLIE, Joan. Moving experiences: A qualitative analysis of health and migration. 
havia assumido até então, e que visava a contribuição no desenvolvimento de cuidados culturalmente sensíveis. ${ }^{4}$ A orientação política assumida a partir daí pressupõe que os próprios utentes se organizem de modo a influenciar a criação e implementação de políticas e serviços adequados às suas necessidades. A efetivação destes processos implica, entre outros aspetos, a formação de grupos dinâmicos e solidários, capazes de representar os interesses dos seus concidadãos e de exercer algum poder de deliberação nos espaços participativos de controle social criados pelo Estado. ${ }^{5}$ Contudo, a literatura evidencia que os imigrantes e as minorias étnicas não estão ainda suficientemente mobilizados para a participação nestes espaços, ${ }^{6}$ o que pode colocar em causa o desenvolvimento de cuidados de saúde culturalmente sensíveis.

Neste artigo, abordamos os itinerários terapêuticos dos imigrantes Cabo-verdianos na Holanda. Fazêmo-lo com o objetivo quer de identificar as barreiras que limitam o acesso dos imigrantes e minorias étnicas aos cuidados de saúde formais Holandeses, quer de desconstruir discursos que depreciam as competências destes grupos e os caracterizam como incapazes de agir de acordo com a lógica de prestação de cuidados vigente no país de acolhimento. Partindo de uma noção de itinerários terapêuticos enquanto práticas individuais e socioculturais adotadas para lidar com os problemas de saúde, ${ }^{7}$ utilizamos uma metodologia qualitativa centrada na interpretação do significado atribuído pelos participantes às trajetórias percorridas na procura de cuidados. Como iremos ver, a pluralidade de práticas e estratégias empregues pelos Cabo-verdianos no enfrentamento dos seus problemas de saúde sustentam a tese de que estes imigrantes não sucumbem à adversidade nem se poupam a esforços para beneficiarem de um bom estado de saúde. Esta manifestação de resiliência é também alvo de atenção neste artigo.

\section{Saúde e resiliência}

A resiliência é um processo positivo, conducente à saúde, que é acionado quando os indivíduos se deparam com situações potencialmente desestruturantes. ${ }^{8}$ Embora a sua concetualização suscite alguma discordância, ${ }^{9}$ a resiliência pode ser entendida, em termos gerais, como:

\footnotetext{
${ }^{4}$ MINISTERIE VAN VWS. Brief over allochtonen in de gezondheidszorg.

${ }^{5}$ DE FREITAS, Claudia. Em busca de um bom médico - Quando "a saúde não tem fronteiras"; IDEM. Do silêncio à participação: cabo-verdianos e saúde mental na Holanda.

${ }^{6}$ DE SAVORNIN LOHMAN, Jacqueline et alii. Evaluatie wet medezeggenschap cliënten zorginstelling; DE FREITAS, Cláudia. Participation in mental health care by ethnic minority users: Case studies from the Netherlands and Brazil.

${ }^{7}$ GERHARDT, op. cit.

${ }^{8}$ SIMÕES, Celeste. Resiliência e saúde.

9 LUTHAR, Suniya; CICCHETTI, Dante; BECKER, Bronwyn. The construct of resilience: A critical
} 
a capacidade que os indivíduos e sistemas (famílias, grupos e comunidades) têm para lidar com sucesso com adversidades ou riscos significativos. Esta capacidade desenvolve-se e modificase ao longo do tempo, é aumentada por factores de protecção do indivíduo, sistema ou envolvimento, e contribui para a manutenção ou promoção da saúde. ${ }^{10}$

Esta definição enfatiza uma noção de resiliência enquanto capacidade adaptativa e um processo interativo entre os indivíduos e o seu meio. Não é, portanto, concebida enquanto atributo inato, ${ }^{11}$ nem tão pouco um processo estanque, ${ }^{12}$ mas antes como uma resposta positiva a fatores de risco causadores de estresse. Esta resposta não se pauta pela passividade nem pelo conformismo, mas por uma atitude que transforma os indivíduos em sujeitos críticos, e intérpretes de uma cidadania ativa e participativa após experiências adversas. ${ }^{13}$

No contexto da saúde, podemos dizer que estamos perante um processo de resiliência quando os indivíduos perseveram perante o sofrimento e limitações causados pela doença e/ou dificuldades em encontrar uma cura, e superam essas adversidades através da mobilização de recursos pessoais e sociais que atuam como fatores protetores. São exemplos destes recursos a confiança dos indivíduos na sua autonomia e auto-eficácia ${ }^{14}$ e o apoio de elementos da sua rede social pessoal (da família ou da comunidade) na obtenção de informação e na formulação de estratégias que lhes permitam aceder, entre outros direitos, à educação, segurança social, serviços de saúde, organizações religiosas, etc. ${ }^{15}$ A ativação destes fatores de proteção pode ser dificultada em situações em que os indivíduos sofrem um processo de desenraizamento e isolamento social associado, por exemplo, a doenças altamente estigmatizadas, como é o caso da doença mental, ou advindo de processos migratórios. ${ }^{16}$

\section{Imigrantes Cabo-verdianos na Holandae sua integração numa sociedade de acolhimento em mudança}

A imigração Cabo-verdiana para a Holanda iniciou-se nos anos 1950 impelida, em grande parte, pela seca e pobreza vividas pela população em Cabo Verde. Os primeiros imigrantes Cabo-verdianos eram, na sua maioria, homens que encontraram emprego na marinha mercante Holandesa e, mais

\footnotetext{
evaluation and guidelines for future work.

${ }^{10}$ MANGHAM, Colin et alii. Resiliency: relevance to health promotion, p. 4.

${ }^{11}$ MASTEN, Ann. Resilience in individual development: Successful adaptation despite risk and adversity.

12 JUNQUEIRA, Maria de Fátima; DESLANDES, Suely. Resiliência e maus-tratos à criança.

${ }^{13}$ NORONHA, Maria Glícia et alii. Resiliência: nova perspectiva na Promoção da Saúde da Família?

${ }^{14}$ RUTTER, Michael. Resilience concepts and findings: implications for family therapy.

${ }^{15}$ GROTBERG, Edith. A guide to promoting resilience in children: Strengthening the human spirit.

${ }^{16}$ INGLEBY et alii, op. cit.
} 
tarde, no porto de Roterdão. ${ }^{17}$ Hoje vivem cerca de 21.000 Cabo-verdianos na Holanda. ${ }^{18}$

Após a independência de Cabo Verde, em 1975, iniciou-se uma segunda vaga de imigração composta por antigos membros do exército, funcionários públicos e professores. ${ }^{19} \mathrm{~A}$ este grupo juntar-se-iam depois dois novos contingentes: um constituído por Cabo-verdianos que haviam sido recrutados para trabalhar em Portugal durante o período de colonização ${ }^{20}$ e outro por mulheres Cabo-verdianas residentes em Itália onde trabalhavam como empregadas domésticas. ${ }^{21}$

Em 1991, com a realização das primeiras eleições multipartidárias em Cabo Verde, surgiu uma terceira vaga de imigração composta sobretudo por jovens estudantes. Continuaram também a chegar migrantes Cabo-verdianos provenientes de Portugal e de Itália. Nesta altura, começou a observar-se um grande aumento do número total de imigrantes na Holanda levando o governo a adotar políticas de imigração mais restritivas e tornando-se mais difícil entrar no país através da reunificação familiar bem como de nele permanecer em situação de irregularidade. ${ }^{22} \mathrm{O}$ casamento passou assim a ser um meio privilegiado de entrada legal na Holanda. Procurando limitar a imigração através desta via, o governo Holandês promulgou uma lei em 1994 que determina um limiar salarial a partir do qual os futuros cônjuges têm direito a solicitar a entrada de parentes através de formação familiar. ${ }^{23}$ Este limiar salarial quase que duplicou na década seguinte. Com efeito, intensificaram-se restrições na política de imigração Holandesa durante os anos 2000. Aos imigrantes não-comunitários passou a ser exigida aprovação num exame de língua e cultura Holandesas antes de ingressarem no país. ${ }^{24}$ Estas medidas têm tornado particularmente difícil a emigração de pessoas com parcos recursos econômicos e baixo nível de escolaridade e podem estar na base da diminuição do número de imigrantes Cabo-verdianos na Holanda observada na última década. ${ }^{25}$

\footnotetext{
${ }^{17}$ GEMEENTEARCHIEF ROTTERDAM. Sporen van migratie in Rotterdam - Kaapverdianen.

${ }^{18}$ CBS. Cijfers Allochtoon Bevolking.

${ }^{19}$ GEMEENTEARCHIEF ROTTERDAM, op. cit.

${ }^{20}$ PIRES, Dóris. Nha tambor. Onderzoek naar het cultureel erfgoed van Kaapverdianen in Rotterdam/ Uma investigação sobre a herança cultural dos Cabo-verdianos em Roterdão.

${ }^{21}$ ANDALL, Jacqueline. Cape Verdean women on the move: 'Immigration shopping' in Italy and Europe.

22 HOLMES-WIJKEN, Bernardette; BOUWMEESTER, Jaap; GROOTSCHOLTE, Miranda. Uitvoering van de Wet Voorkoming Schijnhuwelijken.

${ }^{23}$ Ibidem.

${ }^{24}$ CARLING, Jørgen. Toward a demography of immigrant communities and their transnational potential.

${ }^{25}$ CBS, op. cit.
} 
A integração dos Cabo-verdianos na sociedade Holandesa tem ocorrido de modo gradual. ${ }^{26}$ Durante muitos anos, os Cabo-verdianos foram apelidados de "imigrantes silenciosos", ${ }^{27}$ um rótulo atribuído por serem vistos como um grupo pacato e trabalhador, que cumpre com as suas obrigações, mas que é pouco assertivo na reinvindicação dos seus direitos.

De fato, a comunidade Cabo-verdiana ainda é percepcionada como sendo algo isolada. A sua orientação sobretudo centrípeta, para o seio do próprio grupo, o fato de ser uma comunidade pequena quando comparada com outras comunidades imigrantes e a sua concentração residencial na região de Roterdão, fizeram com que adquirisse pouca visibilidade no país de acolhimento, reafirmando a sua condição de minoria entre minorias. Talvez por isso os Cabo-verdianos tenham sido excluídos dos programas criados pelo governo para apoiarem os imigrantes até aos anos 1990. Com efeito, pouco se soube sobre as necessidades dos Cabo-verdianos até estes serem incluídos em estudos sobre a educação e a saúde da população, que demonstraram problemas nestas áreas. ${ }^{28}$ Sendo que este artigo tem como tema central a saúde, detenhamos de seguida a nossa atenção sobre esta questão.

Em 2000, quando saíram os primeiros estudos sobre o estado de saúde dos Cabo-verdianos, observou-se que, apesar da ausência de queixas, muitos sentiam dificuldades psicossociais ${ }^{29}$ para as quais não procuravam cuidados formais de saúde mental. ${ }^{30}$ Nessa altura, a Holanda estava na linha da frente dos países empenhados na adaptação dos serviços de saúde à diversidade étnica e cultural dos seus usuários e havia criado vários programas de promoção de saúde destinados a atender às necessidades específicas de alguns grupos de imigrantes. Esses estudos permitiram resgatar os Cabo-verdianos da situação de invisibilidade em que se encontravam e torná-los beneficiários de intervenções de saúde pública. De entre essas intervenções destaca-se um projeto de promoção de saúde mental designado Projeto Apoio. Este projeto permitiu que muitos Cabo-verdianos obtivessem acesso a cuidados de saúde mental e fossem empoderados para terem uma voz atuante acerca da qualidade desses mesmos cuidados. ${ }^{31}$

${ }^{26}$ DE FREITAS, Cláudia. Cape Verdean migrants in the Netherlands: socio-demographic profile, identity and integration.

${ }^{27}$ IDEM. Do silêncio..., op. cit.

${ }^{28}$ HUISKAMP, Nelleke; VIS, Henk; SWART, Wim; VOORHAM, Toon. Gezond in kaart. Allochtonen, gezondheidsproblemen en preventiemogelijkheden in kaart gebracht; DIEPERINK, Cathrien; VAN DIJK, Rob; WIERDSMA, André. GGZ voor allochtonen. Ontwikkelingen in het zorg in de regio Rotterdam, 1990-1998; ISEO/COS. Minderhedenmonitor 2002.

${ }^{29}$ HUISKAMP et alii, op. cit.

${ }^{30}$ DIEPERINK, VAN DIJK, WIERDSMA, op. cit.

${ }^{31}$ DE FREITAS, Cláudia. Oportunidades de mudança: uma voz Cabo-verdiana nos cuidados de saúde 
A importância de uma participação ativa no planeamento e avaliação de serviços de saúde é cada vez mais importante na Holanda. Tal como mencionado na introdução deste artigo, em 2004 o governo Holandês deixou de assumir responsabilidade sobre a promoção de cuidados culturalmente sensíveis. ${ }^{32}$ Hoje, cabe aos prestadores de serviços a decisão de adaptarem (ou não) os seus cuidados de saúde às necessidades dos imigrantes e minorias étnicas, o que é tanto mais provável quanto mais estes grupos manifestem essa necessidade e vontade. Para além disso, o governo autorizou a criação de serviços de saúde "categoriais" 33 , isto é, serviços destinados a grupos específicos (como por exemplo os imigrantes Turcos). Sendo uma boa parte da prestação de cuidados de saúde co-financiada pelas agências de seguros, é de esperar que apenas os grupos com maior expressão numérica e visibilidade sejam alvo de interesse do mercado. Este contexto poderá colocar em causa o acesso das "pequenas minorias" a cuidados de saúde adaptados às suas necessidades, particularmente perante o cenário de provável perda de profissionais culturalmente competentes das equipas dos serviços "gerais" para os serviços "categoriais". Assim, é de ressaltar o envolvimento dos Cabo-verdianos nas iniciativas de promoção de saúde mental desenvolvidas pelo Projeto Apoio, o que não só lhes tem permitido adquirir maior visibilidade e rebater a imagem de "imigrantes silenciosos", como igualmente tem contribuído para promover a sua integração numa sociedade de acolhimento assomada por grandes mudanças ${ }^{34}$ e que exige uma significativa capacidade de resiliência aos seus grupos minoritários. Os imigrantes Cabo-verdianos continuam, no entanto, a sentir algumas dificuldades no acesso aos cuidados formais de saúde Holandeses. Este e outros temas serão alvo de discussão noutras secções deste artigo.

\section{Métodos}

Os resultados que aqui apresentamos baseiam-se em dois estudos qualitativos realizados junto da comunidade Cabo-verdiana residente em Roterdão, na Holanda, tendo por base um projeto comunitário criado para a promoção da saúde mental e do acesso dos Cabo-verdianos aos cuidados de saúde formais Holandeses - o Projeto Apoio. Ambos os estudos compreenderam uma análise documental, a elaboração de um diário de campo das observações executadas junto de atividades do referido projeto (por exemplo,

mental Holandeses.

${ }^{32}$ MINISTERIE VAN VWS, op. cit.

${ }^{33}$ VAN MENS-VERHULST, Janneke; RADTKE, Lorraine. Intersectionaliteit en Sociale Inclusie: Het Ei... van Troje. Deel 2: Het Paard van Troje.

${ }^{34}$ DE FREITAS, Cláudia. Participation in mental health care by ethnic minority users: Case studies from the Netherlands and Brazil. 
sessões de informação e grupos de ajuda mútua) e a realização de entrevistas semidiretivas em profundidade com Cabo-verdianos e outros informanteschave ligados à área da saúde, nomeadamente, assistentes sociais, enfermeiros, psicólogos, membros de organizações de utentes e, pesquisadores. O primeiro estudo centrou-se nas perceções dos Cabo-verdianos sobre os profissionais de saúde na Holanda e na forma como estes influenciam a utilização de cuidados formais no país de acolhimento. Inclui uma amostra de sete utentes Cabo-verdianos e cinco informantes-chave e realizou-se em 2003. ${ }^{35}$ O segundo estudo incidiu no envolvimento dos utentes Caboverdianos em espaços participativos de controle social no campo da saúde. Inclui uma amostra de doze Cabo-verdianos e de trinta informantes-chave ligados à participação cidadã em saúde e foi realizado entre 2005 e $2006 .{ }^{36}$

As entrevistas foram conduzidas nos locais indicados pelos participantes (nomeadamente, em suas casas, locais de trabalho e nas instalações do projeto Apoio) e tiveram uma duração média de uma hora e meia. Todas as entrevistas foram gravadas com o consentimento dos participantes, após Ihes terem sido explicados os objetivos dos estudos em questão e garantido sigilo sobre a sua identidade. Os dados recolhidos foram analisados com base na teoria enraizada ${ }^{37}$ e nos procedimentos de comparação constante e codificação aberta, axial e seletiva. ${ }^{38}$ Os resultados são ilustrados a partir de trechos das entrevistas sendo os participantes identificados através de pseudónimos.

\section{Itinerários terapêuticos}

A análise das práticas e estratégias adotadas pelos imigrantes Cabo-verdianos em Roterdão na procura de soluções para os seus problemas de saúde permitiu a identificação de uma multiplicidade de itinerários terapêuticos que se estendem para além das fronteiras do país de acolhimento, passando por Cabo Verde e por países terceiros como Portugal e França.

Os itinerários identificados abrangem três tipos de sistemas de cuidados de saúde que designaremos de cuidados informais, formais e transnacionais. Os cuidados informais estão relacionados com as respostas encontradas a partir da comunidade de referência dos doentes. Incluem tratamentos recomendados por familiares, vizinhos e amigos, a automedicação, práticas religiosas e terapêuticas tradicionais e mágicas (por exemplo, o recurso a herbalistas, curandeiros e bruxas). Os cuidados formais incluem os serviços

35 IDEM. Em busca..., op. cit.

${ }^{36}$ IDEM. Participation in mental health..., op. cit.

${ }^{37}$ GLASER, Barney; STRAUSS, Anselm. The discovery of grounded theory: strategies for qualitative research.

${ }^{38}$ STRAUSS, Anselm; CORBIN, Juliet; Basics of qualitative research. Techniques and procedures for developing grounded theory. 
e profissionais de saúde cujas práticas são reconhecidas e reguladas pelo Estado. Apresentam, por norma, um caráter marcadamente biomédico, sendo reembolsáveis por meio de seguros de saúde, ${ }^{39}$ no caso da Holanda, ou comparticipados pelo Estado, no caso dos serviços públicos de saúde em Cabo Verde, Portugal e em França. ${ }^{40}$ Os cuidados transnacionais abrangem o conjunto de trajetórias de cura adotado por indivíduos cuja dupla pertença a redes e contextos desterritorializados lhes permite aceder a recursos que não se encontram circunscritos pelas fronteiras de um único país ou naçãoestado. Podem incluir práticas associadas aos cuidados formais e informais.

A pluralidade de estratégias terapêuticas empregues pelos Cabo-verdianos é influenciada pelas suas racionalidades leigas acerca da saúde e pelos contextos socioculturais e políticos por onde transitam. Essas estratégias são frequentemente ativadas em simultâneo, originando múltiplas incursões por percursos terapêuticos distintos. Noutros casos, ativam-se percursos diferentes de forma sequencial, quando a primeira trajetória adotada não satisfaz integralmente as necessidades sentidas. Uma caraterística comum a todos os Cabo-verdianos afetados pela doença mental é o secretismo com que procuram e utilizam os cuidados para lidar com este problema, algo que reflete, em toda a sua evidência, o estigma associado à loucura. De seguida, apresentaremos os vários itinerários terapêuticos percorridos pelos Cabo-verdianos no enfrentamento dos seus problemas de saúde.

\section{Cuidados de saúde informais}

Quando confrontados com um problema de saúde os Cabo-verdianos recorrem, em primeira instância, a processos de ajuda mútua. Estes processos pressupõem um entendimento comum do problema e envolvem um compromisso pessoal e acordo tácito recíprocos quanto ao modo de retribuição. Os canais de ajuda mútua são acionados de forma informal e célere e mantêm-se ativos até que o sujeito seja efetivamente ajudado ou até que a gravidade do problema exija o recurso a ajuda externa.

Os Cabo-verdianos encaram a saúde-doença com base em racionalidades leigas fundadas num "repertório Cristão-espiritual"41, que

\footnotetext{
${ }^{39}$ A Holanda tem um dos sistemas de saúde mais mercadorizados da Europa. Desde 2006, todas as pessoas residentes na Holanda são obrigadas por lei à aquisição de um seguro de saúde individual junto de uma seguradora privada da sua escolha. As pessoas cujos rendimentos não são suficientes para suportar os custos do seguro de saúde beneficiam de um subsídio do Estado Holandês para o efeito.

${ }^{40}$ Em Cabo Verde, Portugal e França existem também serviços de saúde privados cuja utilização pode eventualmente ser reembolsada através de seguros de saúde efectuados na Holanda, dependendo do tipo de contrato feito pelo segurado.

${ }^{41}$ BEIJERS, Huub. People with a mission. Meanings of psychosocial distress of Cape Verdeans in The Netherlands.
} 
contempla igrejas e casas de devoção como importantes pontos comunitários onde se podem encontrar soluções para os problemas que vão surgindo. A religião, sob as vertentes do Catolicismo Romano, do Pentecostalismo Carismático e do Racionalismo Cristão, ${ }^{42}$ é particularmente relevante, pois possibilita, através da sua cosmologia, simbolismo e rituais, a compreensão e tratamento dos problemas e oferece um contexto institucional para o seu reconhecimento. ${ }^{43} \mathrm{O}$ Racionalismo Cristão é praticado no Centro Redentor. ${ }^{44}$ Existem em Roterdão dois locais de culto onde os Cabo-verdianos se reúnem três vezes por semana em sessões de "limpeza psíquica", que têm geralmente muita afluência. Estas sessões são um espaço de reflexão e partilha que proporcionam alívio e conforto, estimulando sentimentos de pertença e de empoderamento que ajudam a suportar as dificuldades quotidianas. Uma outra instituição, a Igreja Universal do Reino de Deus (IURD), de Roterdão, de cariz Pentecostal Carismático, possui uma grande implantação junto da comunidade Cabo-verdiana e encontra-se em crescimento, suscitando também alguma controvérsia. ${ }^{45}$ A maioria dos Cabo-verdianos na Holanda, porém, postula o Catolicismo-Romano. Nesta vertente, a paróquia da Nossa Senhora da Paz, também em Roterdão, desempenha um papel fundamental no apoio e fortalecimento da comunidade Cabo-verdiana, quer em tempos de prosperidade, quer na adversidade. A paróquia é parte integrante da comunidade, um local de encontro e de união onde se partilham notícias e atualizam novidades sobre Cabo Verde e também um local de apoio onde se promovem grupos de auto-ajuda organizados por profissionais de Serviço Social e de apoio comunitário. O fortalecimento da comunidade e a preservação das suas idiossincrasias culturais é um aspeto central da política da paróquia, ${ }^{46}$ na qual a língua é veículo privilegiado de interação e de partilha. As divergências políticas são, nesse contexto, ultrapassadas.

As racionalidades leigas que enformam as crenças relativas à saúde, e mais particularmente os itinerários de procura de ajuda no contexto do enfrentamento de problemas do foro interpessoal ou espiritual, contemplam igualmente o recurso a curandeiros. Porém, informações sobre o seu trabalho escasseiam, pois as pessoas temem ser-lhes associadas, bem como a feiticeiros ou bruxas, por poder suspeitar-se de estarem envolvidas em algo demoníaco. Tal reconhecimento configuraria uma ameaça à imagem de civilidade e modernidade que as pessoas

42 Ibidem.

${ }^{43}$ BHUGRA, Dinesh. Religion and mental health.

${ }^{44}$ VASCONCELOS, João. Lusophone spirits on a creole island.

${ }^{45}$ ORO, Ari; SEMÁN, Pablo. Brazilian Pentecostalism Crosses National Borders.

${ }^{46}$ GRAÇA, António da. Associativismo Cabo-Verdeano em Roterdão e integração política. 
procuram cultivar, ${ }^{47}$ apesar de as práticas do curandeirismo se encontrarem intimamente arreigadas na tradição cultural Cabo-verdiana. Embora muitos participantes tenham admitido o recurso aos serviços de curandeiros pelo menos uma vez, quer na Holanda, quer noutros países (nomeadamente em França, Portugal ou Cabo Verde), mostraram-se de um modo geral relutantes em falar deste tipo de tratamento complementar. $\mathrm{O}$ recurso a herbalistas ou a videntes e leitores de aura no país de acolhimento foi mais prontamente discutido, talvez por ser mais facilmente aceite no seio da comunidade.

Os cuidados informais obtidos a partir dos locais comunitários de consolação e devoção descritos evidenciam, por outro lado, as limitações do capital social dos Cabo-verdianos na Holanda. ${ }^{48}$ No contexto da comunidade Cabo-verdiana, os papéis sociais tendem a sobrepor-se, ${ }^{49}$ existindo pouco contato entre os seus membros e outros segmentos da sociedade Holandesa que, com algumas exceções (alguns imigrantes Surinameses, por exemplo), não partilham as suas racionalidades leigas sobre saúde. Este enquadramento contribui, com efeito, para o isolamento da comunidade e para a perpetuação de fronteiras rígidas entre esta e o sistema sócio-institucional do país de acolhimento, com efeitos práticos perniciosos, designadamente as dificuldades em erigir pontes com os representantes de programas governamentais e de serviços de saúde orientados para a satisfação das necessidades dos imigrantes e minorias étnicas. Neste aspeto, tem sido fundamental o papel desempenhado pela paróquia Católica-Romana e pelo projeto comunitário de promoção da saúde mental - o Projeto Apoio -, que estabeleceram parecerias funcionais com os serviços de saúde mental locais.

\section{Cuidados de saúde formais}

Na Holanda, os cuidados de saúde (mental) formais são acessíveis somente através de referenciação por parte de um médico de clínica geral ou de um técnico de Serviço Social. É comum, entre os Cabo-verdianos, haver experiências negativas com os cuidados de saúde mental, nomeadamente no que respeita à ajuda atempada e incondicional. Pacientes reportam que é frequente a prescrição de analgésicos nas consultas (usualmente Paracetamol), independentemente da natureza da situação ou queixa apresentada: ${ }^{50}$

Quando vou lá [ao Posto Médico] só fico uns dez minutos na sala do médico. Ele não vê o meu sangue ou o coração. Ele não

\footnotetext{
${ }^{47}$ CABRAL, Nelson. Notes sur le catholicisme aux Iles du Cap-Vert.

${ }^{48}$ GRAÇA, op. cit.

${ }^{49}$ BEIJERS, People with..., op. cit.

${ }^{50}$ DE FREITAS, Em busca..., op. cit.
} 
A resiliência da saúde migrante: itinerários terapêuticos plurais e transnacionais

examina o meu corpo para ver como é que eu estou. Ele apenas observa e ouve o que eu digo, dá-me a minha medicação habitual para o Lúpus e se eu me queixo de alguma dor que possa ter ele dá-me Paracetamol. E é tudo. (Paula)

A prescrição de Paracetamol é muitas vezes usada enquanto metáfora para tratamentos ineficazes: "Eles [técnicos de saúde] estão menos interessados no paciente e os tratamentos não são tão eficazes. Aqui eles dão um tratamento geral para todos. Receitam Paracetamol para tudo, mas nem todos precisamos disso" (Dulce).

Alguns Cabo-verdianos sabem que o "tratamento Paracetamol", que consideram inadequado e desqualificador da sua legitimidade enquanto pacientes, pode ser substituído por tratamentos mais adequados às suas necessidades. Tal possibilidade, porém, requer a capacidade de persuadir os profissionais de saúde quanto à autenticidade das queixas ou sintomas apresentados e da subsequente necessidade de cuidados:

A primeira vez que consultei o meu médico atual ele foi difícil. Mesmo quando os meus filhos precisavam de ser examinados... Em Portugal quando sentes alguma coisa os médicos enviam-te imediatamente para um especialista. Aqui é preciso ir ao médico várias vezes e falar com ele muito seriamente e explicar-lhe que não te sentes bem. (Judite)

A necessidade de "comprovar" a veracidade das queixas é interpretada pelos pacientes como uma confrontação direta à sua integridade, credibilidade e legitimidade. Quando, por fim, logram entrar no sistema de saúde, são muitas vezes confrontados com a compartimentalização e fragmentação que caracterizam o sistema de saúde Holandês.

Às vezes o médico examina o teu problema. E às vezes as coisas não são fáceis de encontrar. E isto é uma coisa importante no caso dos médicos na Holanda e em Cabo Verde. Em Cabo Verde um médico faz tudo. (...) mas na Holanda tens que ir a vários médicos. (Miguel)

Miguel considera que esta especialização gera uma morosidade desnecessária e uma burocracia que compromete a experiência de integridade corporal, biográfica e social do paciente.

Uma forma de evitar os "guardiães do sistema", isto é, os médicos de clínica geral que atuam como filtro de entrada nos serviços de saúde, consiste em aceder aos cuidados de saúde através do denominado "atalho Americano". ${ }^{51}$ Este mecanismo é usado por muitos imigrantes no Ocidente

${ }^{51}$ BHUI, Kamaldeep; BHUGRA, Dinesh. Explanatory models for mental distress: implications for 
para acederem diretamente a serviços especializados ou de emergência ${ }^{52}$ que, por vezes, também dão entrada nesses serviços através do sistema criminal. Tal método baseia-se em pedidos de ajuda imediata, em situações multiproblemáticas e/ou de crise, frequentemente acompanhadas de intervenções ou mediações de outros profissionais que não os de saúde mental (como por exemplo, a polícia, os bombeiros, etc.). Todavia, o que é considerado um modo irregular de aceder aos cuidados de saúde num país pode ser, como veremos adiante, perfeitamente regular noutro.

As dificuldades encontradas pelos imigrantes e minorias étnicas no acesso ao sistema de saúde são frequentemente atribuídas a défices de literacia em saúde por parte daqueles. Os imigrantes, por sua vez, tendem a considerar essas dificuldades uma consequência do défice de qualidade dos cuidados prestados. Os técnicos de saúde na Holanda são caracterizados pelos Cabo-verdianos como desatentos, limitadores, ineficazes, generalizadores e indiferentes. Na sua opinião, um "bom médico" reúne qualidades tais como boa capacidade de comunicação (atento, empático, disponível, cuidador), capacidade de providenciar uma rápida resolução do problema apresentado e disponibilidade para centrar o ato médico no paciente (sendo protetor, sensível aos mais carenciados e focado nas necessidades do paciente). ${ }^{53}$

A principal lacuna comunicacional com o sistema de saúde reside pois no nível interpessoal, entre médicos e pacientes, embora as dificuldades surjam também ao nível institucional, onde as regras, intenções e orientações relativas aos cuidados de saúde a adotar são frequentemente mal compreendidas. ${ }^{54}$ Para além destes aspectos, os problemas ocorrem igualmente aos níveis afetivo e interpretativo: a compreensibilidade mútua na construção de uma relação de confiança é considerada deficitária, pelo que as dimensões morais e sociais dos problemas não são atendidas. Os médicos deixam assim de ser percebidos como peritos incontestados e a sua autoridade social fica comprometida, também devido ao fato de estes se sentirem pouco confortáveis na abordagem à dimensão social dos problemas de saúde. Assiste-se à tendência crescente de os cuidados de saúde transformarem o sofrimento social em doenças e diagnósticos, negligenciando, em muitos casos, a origem e implicações morais e sociais do sofrimento. Sentimentos de rejeição, vulnerabilidade ou descrédito emergem entre os pacientes,

\footnotetext{
clinical practice and research.

52 Ibidem.

${ }^{53}$ DE FREITAS, Em busca..., op. cit.

${ }^{54}$ BEIJERS, Huub. Within the Cape Verdean community you always come to a solutionMeanings of psychosocial distress and experiences with mental health care of Cape Verdean immigrants in The Netherlands.
} 
dificultando o estabelecimento de relações de confiança com o sistema e com os profissionais de saúde e reforçando a sua falta de legitimidade enquanto cidadãos que necessitam de cuidados.

Como vimos anteriormente, a solução apontada pelos governantes Holandeses para melhorar a capacidade de resposta dos serviços de saúde passa pela adoção de um papel mais ativo por parte dos cidadãos cujas necessidades não se encontrem completamente satisfeitas. ${ }^{55}$ Kickbusch e colegas ${ }^{56}$ definem reflexividade como uma caraterística central da literacia em saúde, que por sua vez se refere aos atributos ou competências necessários para lidar com a instabilidade das condições e pressuposições do setor dos cuidados de saúde. Esta reflexividade pode evoluir até uma estratégia visando a mudança do modo como a saúde é compreendida e gerida. Tal não se esgota somente num processo de emancipação individual, mas traduz-se igualmente na participação dos utentes dos cuidados de saúde mental ${ }^{57}$ e no empoderamento da comunidade, na qual os imigrantes readquirem controlo sobre os seus corpos e introduzem a migração, a cultura e as circunstâncias sociais quotidianas enquanto fatores relevantes no modelo de tratamento biomédico. ${ }^{58}$

\section{Cuidados de saúde transnacionais}

Historicamente, as soluções para os problemas da população em Cabo Verde emergiram mais prontamente a partir da comunidade local e da diáspora do que a partir do Estado. Durante o período colonial, Portugal negligenciou os Cabo-verdianos em tempos de grandes necessidades, ${ }^{59} \mathrm{e}$ a solidariedade diaspórica (i.e.ajuda financeira) estabeleceu-se como um recurso indispensável à república, algo que continua a verificar-se até aos dias de hoje. Herdando uma história de migrações de dois séculos, praticamente todos os residentes em Cabo Verde mantêm contato com familiares e amigos espalhados pelo mundo, facilitado, nos dias de hoje, pelo acesso a transportes mais baratos e às novas tecnologias de comunicação.

Estas conexões transnacionais mantêm ativas as relações pessoais e constituem "sistemas de referência" alternativos. Contrariamente aos exemplos de outras comunidades migrantes, ${ }^{60}$ a procura transnacional de

\footnotetext{
${ }^{55}$ MINISTERIE VAN VWS, op. cit.

${ }^{56}$ KICKBUSCH, Ilona; MAAG, Daniela; SAAN, Hans. Enabling healthy choices in modern health societies.

${ }^{57}$ DE FREITAS, Participation in..., op. cit.; IDEM. Oportunidades de..., op. cit.

58 BEIJERS, Huub; DE FREITAS, Cláudia. Cape Verdean's pathways to health: local problems, transnational solutions.

${ }^{59}$ MEINTEL, Deidre. Race, culture and Portuguese colonialism in Cape Verde.

${ }^{60}$ MESSIAS, DeAnne. Transnational health resources, practices, and perspectives: Brazilian immigrant women's narratives; MURPHY, Eleanor; MAHALINGAM, Ramaswami. Transnational ties and mental health of Caribbean immigrants.
} 
cuidados de saúde não é restrita ao país de origem, mas estende-se até vários países da diáspora. ${ }^{61}$ Manuel expressa de forma evidente esta perspetiva desterritorializada da saúde e dos cuidados de saúde:

Em Cabo Verde há médicos que falam a nossa língua, mas a saúde não tem fronteiras. Quando alguém tem um problema de saúde e procura ajuda, não há fronteiras. Se você sabe que há bons médicos na Suíça, você vai até lá. Se está em Portugal e ouve que há melhores médicos em Espanha, você vai a Espanha. Quando estás à procura para ter mais saúde, não há fronteiras. Você vai onde é preciso.

Dulce, uma mulher de cinquenta e quatro anos que viveu em Portugal e em França antes de se estabelecer na Holanda, fala da sua experiência com a doença e os cuidados de saúde:

Em Portugal tive que marcar uma consulta para o especialista... às vezes passava um mês até ter a consulta. Em França posso ser atendida pelo médico imediatamente. Um mês é tempo suficiente para eu ter uma crise. Conheço muito bem os meus sintomas e sei quando é que preciso de ver o especialista diretamente. (...) Aqui [e. g. na Holanda] eu preciso de ir sempre ao médico de família. Não posso decidir sozinha ir diretamente ao especialista (...) Quando sinto que estou prestes a ter uma crise devido à minha doença [e.g. anemia hereditária das células falciformes] eu vou lá. Às vezes nem sequer vou ao médico aqui. Se ainda estou capaz apanho o avião e vou ao médico a França. Lá eu posso marcar uma consulta diretamente com o especialista. (...) É preciso fazer muita coisa. Preciso de ir a um dentista mas não o faço aqui. Estou à espera de poder ir a França. (...) Ainda pago a minha Segurança Social em França e posso ter cuidados lá. Não vou deixar de pagar porque aqui não consigo ter os cuidados de que preciso. Por isso eu tomo o meu tempo e cuido da minha saúde lá.

Enquanto navegava pelo sistema de saúde Holandês, Dulce foi confrontada com a necessidade de negociar com o seu médico de clínica geral o encaminhamento para um especialista. No entanto, o diagnóstico de uma doença crónica desde cedo tornou-a especialista na sua doença e no contato com diferentes tipos de profissionais e sistemas de saúde. Dulce escolheu deliberadamente os cuidados de saúde Franceses pela rapidez no acesso a cuidados especializados. Este percurso alternativo permite-lhe articular o seu direito ao controlo da gestão da sua doença com a maximização dos seus

\footnotetext{
${ }^{61}$ DE FREITAS, Cláudia. 'Health has no borders': Cape Verdean immigrants in the Netherlands and the transnational quest for health care across Europe.
} 
A resiliência da saúde migrante: itinerários terapêuticos plurais e transnacionais

recursos transnacionais e assim contornar o "tratamento do Paracetamol", reafirmando a sua legitimidade enquanto paciente e, por fim, o seu bem-estar.

Os recursos para os quais é solicitada ajuda ou aconselhamento vão para além dos cuidados providenciados pelos médicos, incluindo, nomeadamente, referências ao uso de medicação transnacional, ajuda de familiares e consultas complementares com "curandeiros". Lucinda, por exemplo, destaca o apoio social e a disponibilidade com que foi atendida quando a mãe a levou de volta para Cabo Verde:

Eu vim para cá [Holanda] em 1982, mas tive problemas. A minha mãe visitou-me nas férias e quando viu que eu estava mal, levou-me de volta a Cabo Verde. (...) Eu estava doente e tinha problemas com o meu irmão, daí a minha mãe ter preferido levar-me com ela. (...) [ $\mathrm{Na}$ Holanda eu tinha] problemas psicológicos, muitos problemas que não conseguia resolver (...), não falava a língua, não conseguia falar, não conseguia apanhar um autocarro ou o metro e não sabia onde moravam outros Cabo-verdianos. Em Cabo Verde fui ajudada pela minha família e por um médico, que me medicou. Depois enviaram-me para uma unidade de saúde mental (...) em Santiago. (...) Mas lá [Cabo Verde] tive outros problemas, como a pobreza. Quando lá regressei, em 1986, colapsei completamente. Tinha estado 4 anos na Europa. A minha mãe trouxe-me contra a minha vontade e quando vi todas aquelas montanhas e as crianças sem roupas, eu fui-me abaixo.

A história de Lucinda mostra que os percursos transnacionais para a saúde nem sempre são uma escolha voluntária e encarada positivamente. Os familiares intervêm assertivamente e o sucesso não está garantido. Lucinda encontra-se entre diferentes lealdades, incapaz de escolher.

O recurso a estratégias transnacionais de saúde constitui outra estratégia. Marta descreve como este processo é colocado em prática. Dada a sua impossibilidade em sair da Holanda devido a dívidas, ela recorre a medicação usada noutros países:

Quando tive um aborto eles disseram que os meus ovários não estavam bem mas o médico sempre disse que eu não tinha nada. Eu tomo estes medicamentos de Portugal que me ajudam a comer e a dormir. Mas se os tomo hoje, tenho dores nos ovários amanhã. Ninguém me prescreveu os medicamentos... mas muita gente toma-os. Quase todos os Cabo-verdianos os tomam. São bons para tudo. Se tens problemas ou ficas zangada, tomas esses medicamentos e dormes bem. Pedi a um amigo para os conseguir em Portugal. Conhecia-o desde [o tempo em que vivia em] Cabo Verde. 
Estes medicamentos são tomados sem supervisão médica. São validados pelo seu uso comum entre os Cabo-verdianos e pelo agrado que estes nutrem pelos cuidados de saúde Portugueses, vistos como fiáveis e familiares. Para além da familiaridade, a necessidade de explicações adicionais e mais holísticas para os problemas de saúde desempenha igualmente um papel importante na escolha dos cuidados. Helena consultou um médico Brasileiro em Paris, um vidente ou médium: "Ele trata-te de uma maneira completamente diferente. (...) Quando entrei ele olhou para mim e disse-me: você sofre de 'formigueiro', pés frios e 'tem a cabeça fraca'"62. Os Cabo-verdianos em Roterdão organizam excursões mensais para irem a este médico em Paris. Curandeiros são também visitados em Portugal, Cabo Verde ou em França. ${ }^{63}$ O recurso a estas soluções transnacionais, mesmo se somente possíveis através de canais indiretos, tais como a "importação de medicamentos", traduzem a determinação em beneficiar de um bom estado de saúde e de ultrapassar as barreiras que impedem o acesso aos cuidados de saúde formais holandeses. Esta dedicação e os percursos terapêuticos utilizados resultam de iniciativas organizadas individual e coletivamente. Quando os Cabo-verdianos não podem viajar para fora do país, devido a parcos recursos financeiros, doenças, constrangimentos legais, ou desconhecimento sobre como aceder a sistemas de saúde estrangeiros, ou ainda devido a contatos sociais mais limitados, a importação de "bons médicos" para a Holanda emerge como uma estratégia viável para assegurar o acesso à saúde.

Recorrer a cuidados de saúde transnacionais comporta, no entanto, algumas desvantagens. É necessário haver disponibilidade de meios adicionais, tais como conhecimento acerca das particularidades dos sistemas de saúde estrangeiros, planeamento de viagens, licenças do trabalho, e recursos financeiros. Estas exigências são possíveis de obter de várias formas, i.e. através da manutenção de seguros de saúde anteriores, poupando dinheiro para situações de emergência ou solicitando ajuda financeira. A ocorrência de "situações de emergência" é imprevisível. Se acontece muitas vezes constitui uma sobrecarga financeira difícil de suportar, originando dívidas e comprometendo a subsistência. Preocupações resultantes de tais circunstâncias são frequentemente referidas como uma importante fonte de estresse psicossocial. Tal como Dulce menciona, ela é por vezes forçada a adiar o tratamento de que necessita.

As redes sociais constituem os principais facilitadores de ajuda e contribuem para a formulação e sustentação de estratégias de procura de

\footnotetext{
${ }^{62}$ BEIJERS, DE FREITAS, op. cit., p. 248.

${ }^{63} \mathrm{Ibidem}$.
} 
cuidados de saúde, que não são restritas às fronteiras de casa ou dos países de acolhimento, mas que se materializam em qualquer outro território da diáspora. Soluções potenciais para os problemas de saúde emergem de várias origens e recursos, frequentemente alargados a múltiplos países. Os participantes nos nossos estudos tornaram claro que quando se trata de procurar e assegurar a saúde é a qualidade que mais conta, e não os determinantes geográficos ou políticos. Os recursos de cuidados de saúde transnacionais alargaram o âmbito das escolhas de tratamentos para os participantes, permitindo o restabelecimento de autonomia e instrumentalidade na seleção dos cuidados, reforçando a auto-confiança e reafirmando a legitimidade enquanto pacientes e cidadãos. Porém, também contribuem para uma distância persistente aos cuidados de saúde locais, inibindo a aquisição das competências necessárias à navegação nesse sistema de saúde.

\section{Considerações finais}

Muito embora a medicalização ${ }^{64}$ da sociedade Holandesa e a crescente mercadorização do seu sistema de saúde tenham consolidado os cuidados formais de saúde e, mais especificamente, a medicina, enquanto racionalidade dominante no enfrentamento da doença, os itinerários terapêuticos percorridos pelos imigrantes Cabo-verdianos residentes nesse país não se cingem somente ao sistema de cuidados formais nem são, tão pouco, constrangidos por fronteiras geopolíticas. Como vimos, as estratégias empregues pelos Cabo-verdianos na resolução dos seus problemas de saúde incluem cuidados formais, informais e transnacionais que são frequentemente utilizados de modo sincrético. Estas práticas são influenciadas por um "reportório Cristão-espiritual"65 que serve de base às racionalidades leigas dos Cabo-verdianos e pelo contexto sociocultural e político do país onde residem. Uma análise detalhada destas práticas deixa antever, no entanto, que a opção por cuidados de saúde transnacionais, por exemplo, não é produto apenas de uma escolha pessoal mas resulta, grosso modo, de impedimentos vários que condicionam o acesso destes imigrantes aos cuidados formais no país de acolhimento. De entre as barreiras encontradas destacam-se a falta de informação sobre os serviços de saúde disponíveis, problemas na relação médico-doente e dificuldades em lidar com a condicionalidade da ajuda prestada. ${ }^{66}$ Estes impedimentos atrasam os processos de restauração de saúde gerando níveis consideráveis de ansiedade e outras manifestações

\footnotetext{
${ }^{64}$ ILLICH, Ivan. The medicalization of life.

${ }^{65}$ BEIJERS, op. cit.

${ }^{66}$ DE FREITAS, Em busca..., op. cit.
} 
de estresse psicossocial. Apesar disso, os Cabo-verdianos reagem, de forma geral, com agência e "inventividade"67 às dificuldades encontradas, enveredando por trajetórias terapêuticas alternativas traçadas a partir da local e/ou além-fronteiras. Esta manifestação de resiliência perante a adversidade materializa-se através da mobilização de recursos materiais e da ativação de redes locais e transnacionais de vizinhança, parentesco e amizade que oferecem alternativas, facilitam percursos e amenizam o impacto negativo da desarticulação percecionada entre as necessidades sentidas e as respostas aos seus problemas de saúde no país de acolhimento.

O recurso a cuidados transnacionais não é uma prática exclusiva dos Cabo-verdianos. Há cada vez mais cidadãos, migrantes ou não, que escolhem realizar viagens internacionais para acederem a cuidados médicos fora dos países onde residem. ${ }^{68}$ Estes "viajantes médicos" não só assumem a responsabilidade de procurar resolver os seus problemas de saúde, como demonstram competências valiosas na obtenção de informação sobre prestadores de serviços estrangeiros e na seleção daqueles que melhor se ajustam às suas necessidades. A procura transnacional de cuidados constitui, portanto, uma prática potencialmente empoderadora que evidencia múltiplas aptidões e grande resiliência da parte de quem a assume. A efetivação de tais recursos não só contribui para a desconstrução de discursos pejorativos sobre as capacidades dos imigrantes em utilizarem os serviços de saúde formais nos países de acolhimento, como põe em evidência as falhas e ineficiências destes serviços.

Existem, porém, algumas desvantagens associadas à transnacionalização do consumo de cuidados de saúde que não devem ser subestimadas. Uma das desvantagens prende-se com a conjugação entre as viagens necessárias e os timings individuais e disponibilidade financeira. Com efeito, alguns dos participantes no nosso estudo protelaram tratamentos além-fronteiras até poderem ter direito a férias ou de poderem comportar os custos que lhe estão subjacentes. Estes atrasos podem originar um agravamento desnecessário dos problemas de saúde. Para além disso, é crível que quando os cuidados transnacionais são vistos como a única possibilidade viável de tratamento possa gerar-se um afastamento dos cuidados formais no país de residência, impedindo a aquisição de informação e práticas necessárias para fazer uso do sistema de saúde. Ora, estas circunstâncias, por sua vez, condicionam a capacidade de identificação de problemas no sistema, bem como de soluções

\footnotetext{
${ }^{67}$ CARAPINHEIRO, op. cit.

${ }^{68}$ MESSIAS, op. cit.; KANGAS, Beth. Traveling for medical care in a global world; GIDEON, Jasmine. Exploring migrants' health seeking strategies: the case of Latin American migrants in London; ORMOND, Meghann. Harnessing diasporic medical mobilities.
} 
A resiliência da saúde migrante: itinerários terapêuticos plurais e transnacionais

que poderiam, num contexto de envolvimento efetivo, ser apresentadas nos espaços participativos de controle social em saúde. ${ }^{69}$

A resiliência evidenciada por grupos de imigrantes que, tal como os Cabo-verdianos, inventam percursos que lhes permitem chegar a soluções alternativas de atenção e cuidados de saúde, não deve ser encarada como uma fonte de desresponsabilização do dever dos governantes de assegurarem a formulação de respostas integrais às necessidades de toda a população. Dito de outro modo, muito embora seja importante investir na promoção da resiliência dos imigrantes e de outros grupos em situação de vulnerabilidade, isso não pode nem deve substituir políticas de combate às desigualdades que estão na base das desvantagens vividas por estes segmentos da população. A ausência de ação por parte dos decisores políticos pode potenciar a "produção e reprodução de lugares marginais ao sistema de saúde, onde se abrigam 'crendices' e "charlatães", ${ }^{70}$ como aliás já foi observado em países como a Inglaterra. ${ }^{71} \mathrm{O}$ investimento no desenvolvimento de cuidados de saúde sensíveis à diversidade (não só étnica como também socioeconómica) é fundamental ${ }^{72}$ num contexto global em que, apesar da sua longa história de migração, muitos países ditos desenvolvidos continuam sem serem capazes de garantir o acesso da totalidade das suas populações a serviços de saúde de qualidade.

\section{Bibliografia}

ALVES, Fátima; BÄCKSTRÖM, Bárbara. Lidar com a doença mental - a pluralidade de sistemas de cuidados e de itinerários terapêuticos: análise comparativa de dois estudos efectuados junto de duas populações residentes em Portugal. Saúde e Sociedade, v. 21, n. 3, 2012, p. 543-557.

ANDALL, Jacqueline. Cape Verdean women on the move: 'Immigration shopping' in Italy and Europe. Modern Italy, v. 4, n. 2, 1999, p. 241-257.

BEIJERS, Huub. People with a mission. Meanings of psychosocial distress of Cape Verdeans in the Netherlands. Amesterdão: University of Amsterdam, 2004.

. Within the Cape Verdean community you always come to a solution Meanings of psychosocial distress and experiences with mental health care of Cape Verdean immigrants in The Netherlands. Trabalho apresentado na International Conference on Cape Verdean Migration and Diaspora, Lisboa, 2005.

BEIJERS, Huub; DE FREITAS, Cláudia. Cape Verdeans' pathways to health: Local problems, transnational solutions. In CARLING, Jørgen; BATALHA, Luís (orgs).

${ }^{69}$ DE FREITAS, Participation in..., op. cit.

${ }^{70}$ CARAPINHEIRO, op. cit., p. 347.

${ }^{71}$ GIDEON, op. cit.

72 WATTERS, Charles et alii. Good practices in mental health and social care for asylum seekers and refugees; PORTUGAL, Rui et alii. Good practices on health and migration in the EU. 
Transnational archipelago. Perspectives on Cape Verdean migration and diaspora. Amsterdam: Amsterdam University Press 2008, p. 237-254.

BHUGRA, Dinesh. Religion and mental health. In BHUGRA, Dinesh (org). Psychiatry and religion: context, consensus and controversies. Nova lorque: Routledge, 1996, p. 1-4.

BHUI, Kamaldeep; BHUGRA, Dinesh. Explanatory models for mental distress: implications for clinical practice and research. The British Journal of Psychiatry, v. 181, 2002, p. 6-7.

CABRAL, Nelson. Notes sur le catholicisme aux lles du Cap-Vert. Revue Française D'études Politiques Africaines, v. 14, n. 165/166, 1979, p. 108-117.

CARAPINHEIRO, Graça. Inventar percursos, reinventar realidades: doentes, trajectórias sociais e realidades formais. Etnográfica, v. V, n. 2, 2001, p. 335-358.

CARLING, Jørgen. Toward a demography of immigrant communities and their transnational potential. International Migration Review, v. 42, n. 2, 2008, p. 449-475.

CBS. Cijfers Allochtoon Bevolking. Voorburg: CBS, 2012. Disponível em: <http:// www.cbs.nl>. Accesso em: 12.02.2013.

DE FREITAS, Cláudia. Cape Verdean migrants in the Netherlands: socio-demographic profile, identity and integration. In ÉVORA, Iolanda (org.). Faces da diáspora: estudos sobre a migração cabo verdiana contemporânea. Lisboa: CESA, ISEG, no prelo, 2013.

. Do silêncio à participação: cabo-verdianos e saúde mental na Holanda. In GÓıS, Pedro (org). Comunidade(s) Cabo-verdiana(s): as múltiplas faces da imigração Cabo-verdiana, Lisboa: Observatório da Imigração/ Alto Comissariado para a Imigração e Diálogo Intercultural, 2008, p. 207-228. Disponível em: $<$ http://www.oi.acidi.gov.pt/modules.php?name=Content\&pa $=$ showpage $\&$ pid $=$ 47>. Acesso em: 26.02.2013.

. Em busca de um bom médico - Quando "a saúde não tem fronteiras". Percepções dos Cabo-verdianos sobre profissionais de saúde na Holanda. Lisboa: Observatório da Imigração/ Alto Comissariado para a Imigração e Minorias Étnicas, 2006. Disponível em: <www.oi.acidi.gov.pt/docs/Col_Teses/6_CF.pdf>. Acesso em 11.01.2013.

'Health has no borders': Cape Verdean immigrants in the Netherlands and the transnational quest for health care across Europe. International Journal of Migration, Health and Social Care, v. 1, n. 1, 2005, p. 19-36.

. Oportunidades de mudança: uma voz Cabo-verdiana nos cuidados de saúde mental Holandeses. In GRAAL (org.). Atas do seminário + Saúde, gênero e imigração, Coimbra: Graal, Projeto SauDar+, 2012, p. 54-59. Disponível em: <www.graal.org.pt/files/atas\%202012.pdf>. Acesso em: 27.01.2013.

. Participation in mental health care by ethnic minority users: Case studies from the Netherlands and Brazil. Tese de Doutoramento. Utrecht: Utrecht University, 2011. Disponível em: <http://igitur-archive.library.uu.nl/ dissertations/2012-0203-200415/UUindex.html>. Acesso em: 11.01.2013. 
A resiliência da saúde migrante: itinerários terapêuticos plurais e transnacionais

DE SAVORNIN LOHMAN, Jacqueline; RIJKSCHROEFF, Rally; OUDENAMPSEN, Dick; VERKUYL, L.; VAN GELDER, K.; VAN OVERBEEK, R. Evaluatie wet medezeggenschap cliënten zorginstelling. Haia: ZorgOnderzoek Nederland, 2000.

DIEPERINK, Cathrien; VAN DIJK, Rob; WIERDSMA, André. GGZ voor allochtonen. Ontwikkelingen in het zorg in de regio Rotterdam, 1990-1998. Maandblad Geestelijke Volksgezondheid, v. 57, 2002, p. 87-97.

ELLIOT, Susan; GILLIE, Joan. Moving experiences: A qualitative analysis of health and migration. Health \& Place, v. 4., n. 4. 1998, p. 327-339.

GEMEENTEARCHIEF ROTTERDAM. Sporen van migratie in Rotterdam Kaapverdianen, 2002. Disponível em: <http://www.gemeentearchief.rotterdam. $\mathrm{nl} /$ sporenvanmigratie $>$. Acesso em: 13.02.2013.

GERHARDT, Tatiana. Itinerários terapêuticos em situações de pobreza: diversidade e pluralidade. Cadernos de Saúde Pública, v. 22. n. 11, 2006, p. 2449-2463.

GIDEON, Jasmine. Exploring migrants' health seeking strategies: the case of Latin American migrants in London. International Journal of Migration, Health and Social Care, v. 7, n. 4, 2011, p. 197-208.

GLASER, Barney; STRAUSS, Anselm. The discovery of grounded theory: strategies for qualitative research. Chicago: Aldine Publications, 1967.

GRAÇA, António da. Associativismo Cabo-Verdeano em Roterdão e integração política. Trabalho apresentado International Conference on Cape Verdean Migration and Diaspora, Lisboa, 2005.

GROTBERG, Edith. A guide to promoting resilience in children: Strengthening the human spirit. Haia: The Bernard van Leer Foundation, 1995.

HOLMES-WIJKEN, Bernardette; BOUWMEESTER, Jaap; GROOTSCHOLTE, Miranda. Uitvoering van de Wet Voorkoming Schijnhuwelijken. Leiden: Research voor Beleid, 2004.

HUISKAMP, Nelleke; VIS, Henk; SWART, Wim; VOORHAM, Toon. Gezond in kaart. Allochtonen, gezondheidsproblemen en preventiemogelijkheden in kaart gebracht. Roterdão: GGD Rotterdam, 2000.

ILLICH, Ivan. The medicalization of life. Journal of Medical Ethics, v. I, 1975, p. 73-77.

INGLEBY, David; CHIMIENTI, Milena; HATZIPROKOPIOU, Panos; ORMOND, Meghann, DE FREITAS, Cláudia. The role of health in integration. In FONSECA, Lucinda; MALHEIROS, Jorge (orgs). Social integration and mobility: education, housing and health. IMISCOE Cluster B5 State of the art report. Lisboa: Centro de Estudos Geográficos, 2005, p. 89-119.

ISEO/COS. Minderhedenmonitor 2002. Roterdão: ISEO, 2003.

JUNQUEIRA, Maria de Fátima; DESLANDES, Suely. Resiliência e maus-tratos à criança. Cadernos de Saúde Pública, Rio de Janeiro, v. 19, n. 1, 2003, p. 227-235.

KANGAS, Beth. Traveling for medical care in a global world. Medical Anthropology, v. 29, n. 4, 2010, p. 344-362.

$\mathrm{KICKBUSCH}$, Ilona; MAAG, Daniela; SAAN, Hans. Enabling healthy choices in modern health societies, 2005. Disponível em: <http://www.ilonakickbusch.com/ 
en/health-literacy/Gastein_2005.pdf>. Acesso em: 29.01.2013.

LUTHAR, Suniya; CICCHETTI, Dante; BECKER, Bronwyn. The construct of resilience: A critical evaluation and guidelines for future work. Child Development, v. 71, n. 3, 2000, p. 543-562.

MANGHAM, Colin; MCGRATH, Patrick.; REID, Graham., STEWART, Miriam. Resiliency: relevance to health promotion - discussion paper. Ontario: Ministry of supply and services. Catalogue no H39-330/101995E, 1995.

MASTEN, Ann. Resilience in individual development: Successful adaptation despite risk and adversity. In WANG, Margaret; GORDON, Edmund (orgs). Educational resilience in inner-city America: Challenges and prospects, New Jersey: Lawrence Erlbaum, 1994, p. 3-25.

MCLAUGHLIN, Kate; OSBORNE, Stephen; FERLIE, Ewan. New public management: Current trends and future prospects. London: Routledge, 2002.

MEINTEL, Deidre. Race, culture and Portuguese colonialism in Cape Verde. Syracuse, NY: Syracuse University, 1984.

MESSIAS, DeAanne. Transnational health resources, practices, and perspectives: Brazilian immigrant women's narratives. Journal of Immigrant Health, v. 4, n. 4, 2002, p. 183-200.

MINISTERIE VAN VWS (Volksgezondheid, Welzijn en Sport). Brief over allochtonen in de gezondheidszorg. S'-Gravenhage, 2004.

MURPHY, Eleanor; MAHALINGAM, Ramaswami. Transnational ties and mental health of Caribbean immigrants. Journal of Immigrant Health, v. 6, n. 4, 2004, p. 167-178.

NORONHA, Maria Glícia; CARDOSO, Paloma; MORAES, Tatiana; CENTA, Maria de Lourdes; Resiliência: nova perspectiva na Promoção da Saúde da Família? Ciência \& Saúde Coletiva, v. 14, n. 2, 2009, p.497-506.

ORMOND, Meghann. Harnessing diasporic medical mobilities. In THOMAS, Felicity; GIDEON, Jasmine (orgs). Migration, health and inequality. London: Zed Books, p. 150-162.

ORO, Ari; SEMÁN, Pablo. Brazilian Pentecostalism Crosses National Borders. In CORTEN, Andre; MARSHALL-FRATANI, Ruth (orgs.). Between Babel and Pentecost: Transnational Pentacostalism in Africa and Latin America. London: Hurst and Company, 2001, p. 181-196.

PIRES, Dóris. Nha tambor. Onderzoek naar het cultureel erfgoed van Kaapverdianen in Rotterdam/ Uma investigação sobre a herança cultural dos cabo-verdianos em Roterdão, Roterdão: Stichting Avanço, 2006.

PORTUGAL, Rui; PADILLA, Beatriz; INGLEBY, David; DE FREITAS, Cláudia; LEBAS, Jacques; PEREIRA MIGUEL, Lebas, José (orgs). Good practices on health and migration in the EU. Lisboa: Instituto Nacional de Saúde Doutor Ricardo Jorge, 2007.

RUTTER, Michael. Resilience concepts and findings: implications for family therapy. Journal of Family Therapy, v. 21, 1999, p. 119-144. 
A resiliência da saúde migrante: itinerários terapêuticos plurais e transnacionais

SILVA, Luisa Ferreira da; ALVES, Fátima. Compreender as racionalidades leigas sobre saúde e doença. Physis Revista de Saúde Coletiva, v. 21, n. 4, 2011, p.1207-1229.

SIMÕES, Celeste. Resiliência e saúde. In MATOS, Margarida Gaspar (orgs.). Comunicação, gestão de conflitos e saúde na escolar. Lisboa: FMH Edições, 2008.

STRAUSS, Anselm; CORBIN, Juliet. Basics of qualitative research. Techniques and procedures for developing grounded theory. Thousand Oaks: Sage Publications, 1998.

VASCONCELOS, João. Lusophone spirits on a creole island. Trabalho apresentado no Portuguese/African Encounters Congress, Providence, 2002.

VAN MENS-VERHULST, Janneke; RADTKE, Lorraine. Intersectionaliteit en Sociale Inclusie: Het Ei... van Troje. Deel 2: Het Paard van Troje. Journal of Social Intervention: Theory and Practice, v. 18, n. 4, 2009, p. 5-21.

WATTERS, Charles; INGLEBY, David; BERNAL, Mariola; DE FREITAS, Cláudia; DE RUUK, Nina; VAN LEEUWEN, Marlous; VENKATESAN, Soumhya. Good practices in mental health and social care for asylum seekers and refugees. Final Report of the project for the European Commission (European Refugee Fund). Canterbury: University of Kent, 2003.

\section{Abstract \\ The resilience of migrant health: plural and transnational therapeutic itineraries}

This article addresses the strategies employed by Cape Verdean immigrants in the Netherlands to deal with health problems.Drawing on qualitative research, it discusses the choice of plural therapeutic itineraries, including the use of informal, formal and transnational healthcare. These pathways are influenced by Cape Verdeans' lay rationalities about health, which are based on a "Christian-spiritual repertoire", and by a sociocultural and political context that limits their access to Dutch formal healthcare services. The plurality of therapeutic itineraries employed by Cape Verdeans is realised through the (re)construction of their lay knowledge about illness, the mobilisation of material resources and the activation of local and transnational social resources. This plurality of health seeking strategies renders evident the resilience of these migrants when confronted with adversities that can impact negatively on their physical, mental and spiritual wellbeing.

Keywords: Therapeutic Itineraries; Resilience; Transnational Healthcare; Cape Verdean Immigrants; The Netherlands.

Recebido para publicação em 28/02/2013.

Aceito para publicação em 05/05/2013.

Received for publication in February, 28 ${ }^{\text {th }}, 2013$.

Accepted for publication in May, 05 ${ }^{\text {th }}, 2013$. 